\section{Negative salience in impressions of character: Effects of extremeness of stimulus information}

\author{
DONALD R. CUSUMANO and MARJORIE H. RICHEY \\ Saint Louis University, St. Louis, Mo. 63103
}

Ss were given incompatible positive and negative information from which to evaluate the character of a stranger. Narrative descriptions of low, medium, or high valence difference were administered in positive-negative or negative-positive order. Ratings were made after each block of information and again a week later. Final ratings indicated a disproportionate influence of negative information at all valence intensities. Originally negative impressions that had been revised upward by positive information reverted to the negative within a week: originally positive impressions that had been revised downward were not subsequently restored.

Several investigators have dealt with the general problem of the relationship between knowledge about and attitude toward a person (e.g.. Anderson. 1965: Asch, 1946; Fishbein, 1963: Osgood. Suci. \& Tannenbaum, 1957; Rosenkrantz \& Crockett, 1965). Fishbein \& Hunter (1964) have proposed that the major current theories in this area may be classified into one of two types, averaging theories or summation theories. The first proposes that the value of the overall attitude is a function of the average amount of affect contributed by all the individual's beliefs about the object. The second holds that the affect associated with all relevant beliefs summates, so that attitudes become more intense as new information of like sign is added.

A recent study by Richey, McClelland. \& Shimkunas (1967) reported results that were interpreted as incompatible with either a simple averaging or a simple summation theory. Equal amounts of equally extreme positive and negative information about an unknown other were provided to $S$ s as a basis for evaluation of his character. Immediate impressions were strongly influenced by order of information (recency), but after a 1 -week interval, all mean ratings had become negative regardless of order of information. The conclusion was drawn that in impressions of character, negative information has a delayed disproportionate influence.

In the discussion of their results, Richey et al mentioned the possibility that the negative salience they found could have been a function of the valence extremeness of their stimulus materials, which differed rather sharply in favorability. It was logically possible that their findings depended on a contrast effect occurring only with materials within a particular range of difference in polarity. Less extreme positive and negative actions by the stimulus person might have canceled each other, or the combination might have yielded a positive impression. On the other hand, if still more extreme descriptions had been used, the Ss might have found it impossible to reconcile them into a unified impression. Investigation of the effect of such differences in valence intensity was the major reason for the present study.

\section{DESIGN}

The experimental design was a 2 by 3 by 3 factorial with repeated measures on the third factor. The independent variables were order of presentation of descriptive information (negative-positive or positive-negative), valence extremeness or intensity of information (high, medium, or low), and trial. The trials were given immediately after the first half of the information, immediately after the second half, and 7 to 9 days later. The major dependent variable was a rating of the character of the stimulus person.

Ss were 180 undergraduates, 90 males and 90 females. Within each sex, assignment to treatments was at random. All members of two classes were tested, and surplus $\mathrm{Ss}$ in each treatment group were discarded randomly.

\section{INSTRUMENT}

The study by Richey et al (1967) used two pairs of descriptive paragraphs with mean favorability ratings of approximately 2 and approximately 6 on a 7-point ordinal scale with the neutral or average point at 4 . One of these pairs was used verbatim as the stimuli of intermediate intensity. Two other pairs of paragraphs with ratings of 3 and 5 (low intensity) and 1 and 7 (high intensity) were constructed for this study by the following method: Standardization Ss first rated the characters of unknown persons from individual sentences describing specific behaviors. Those most reliably rated near the desired scale points were then combined into positive and negative paragraphs, which were rerated by other $S$ groups and revised until the appropriate paragraph values were obtained. Each paragraph, whether positive or negative, contained five statements, two describing interactions of the stimulus person with co-workers and one each with his wife, children, and parents. Examples of the new paragraphs are given below:

Low-Intensity Positive $\left(\mathrm{P}_{5}\right)$

Although he did not speak out against the practice. $C$ did not enforce an unfair personnel policy of his company; all employees benefited from the resulting decision to change the practice. If he has not had time to give his secretary advance notice, he tells her that she can do rush assignments the next day rather than staying overtime. When he saw that his wife was overworked, he had his children do more of the work around the house. $C$ moved to a different location where the weather is more suitable to the health needs of his little girl, although she would probably have been able to get along adequately in the other location. He occasionally writes his elderly parents and at times sends his wife to stay with them when either is ill.

Low-Intensity Negative $\left(\mathrm{N}_{3}\right)$

When $C$ perceived a subordinate of his as a potential rival, he stopped assigning the subordinate as many jobs in which he could demonstrate his competence. When a superior praises a report that originates in C's office, $\mathrm{C}$ sometimes does not bother to tell him that others actually had more to do with preparing it than he did. At a party which he and his wife attend together, he usually compliments the appearance of some of the other women there. C sometimes misses a Parents' Night at school or Scout meetings if he has had a fatiguing day. He contributes to the support of his parents in an emergency, but seldom offers at other times.

For purposes of comparison, examples of statements from the medium- and high-intensity pairs are also offered. The last negative statement in the high-intensity pair reads: "He never writes to his elderly parents and very rarely visits them, even though they live only about an hour's drive from his home." The corresponding statement of medium-intensity pair reads: "He contributes nothing to the financial support of his elderly parents, who live on a meager pension, although he buys a new car for himself every year."

\section{PROCEDURE}

Ss were given a first block of information, either positive or negative. and asked to rate the character of the stimulus person on the 7-point scale described above. After the initial rating, they were given as a diversion the task of drawing two human figures. Fifteen minutes were allowed for the drawings. 
Table 1

Means of Character Ratings Over Trials

\begin{tabular}{lccc}
\hline & \multicolumn{3}{c}{ Trial } \\
\cline { 2 - 4 } Group & 1 & 2 & 3 \\
& $\mathrm{M}$ & $\mathrm{M}$ & $\mathrm{M}$ \\
\hline NP $_{1-7}$ & 1.40 & 5.33 & 2.56 \\
NP $_{2-6}$ & 2.00 & 5.33 & 2.63 \\
NP $_{3-5}$ & 2.86 & 4.63 & 3.20 \\
PN7-1 & 6.80 & 2.10 & 2.30 \\
PN $_{6-2}$ & 5.96 & 2.10 & 2.53 \\
PN5-3 $_{5}$ & 4.90 & 2.86 & 2.86 \\
\hline
\end{tabular}

Then each group was given a second, incompatible block of information introduced with the statement, "The following is additional information concerning the same person about whom you read on page 1." Having read the second paragraph, $S s$ again rated the stimulus person on the basis of "all information now available." They also wrote a free paragraph describing their impressions of his character. To test for persistence of the impressions, all Ss were asked to rate the stimulus person a third time 1 week to 9 days following the initial ratings. They were also asked to list everything they could remember about him.

\section{RESULTS}

Summary statistics are given in Table 1 . Since the design required that paragraph pairs comprise positive and negative stimuli of equal polarity, a check of this manipulation was made by comparing the first-trial ratings of the separate $P$ and $N$ paragraphs in each pair in terms of their respective deviations from 4.0. Differences were insignificant in each case $(t=1.53$, $.13,1.05$ for high-, medium-, and low-intensity paragraphs, respectively; $\mathrm{df}=58$; all ps $>.05$ ).

Preliminary analysis of variance established that there was a main effect for trials (decline in favorability of ratings over trials), a main effect of order ( $P N>N P$ ), and no main effect for intensity. There was an interaction of Trials by Order and a second-order interaction of Trials by Order by Intensity.

Negative vs Positive Influence

Mean differences on Trials 2 and 3 were of most interest to the hypothesis. Relevant comparisons were done with Duncan's Multiple Range Test $(\alpha=.05)$. On Trial 2, given immediately after presentation of the dissonant paragraph, means at all intensity levels showed a significant recency effect $\left(\mathrm{NP}_{2 \text { nd }}>\mathrm{PN}_{2 \mathrm{nd}}\right)$. A week later, however, the order effects had largely disappeared $\left(\mathrm{NP}_{3 \mathrm{rd}}=\mathrm{PN}_{3 \mathrm{rd}}\right)$. The originally positive ratings, which had been revised negatively on Trial 2, remained negative on Trial 3 $\left(\mathrm{PN}_{2 n d}=\mathrm{PN}_{3 \mathrm{rd}}\right)$. The originally negative ratings, which had been revised positively on Trial 2, however, all showed a significant reversion toward their original negative values on Trial 3 $\left(N_{3 \text { rd }}<N_{2 n d}\right)$. To test for absolute, as well as relative, negativity of the final ratings, $t$ was calculated for the difference between each final mean and the midpoint of the rating scale, 4.0 , using the standard error of the cell mean as the error term. In the order given in the table, these values were $6.55,5.48,3.81,8.95,6.39,5.43$; $\mathrm{df}=29$; all $\mathrm{ps}<.01$. Thus all were significantly negative.

There was also a trend toward negativity as early as the second trial. When a comparison was made of the respective deviations of the $\mathrm{PN}_{2}$ nd and $\mathrm{NP}_{2}$ nd means from a neutral rating of 4 , it was shown in each case that the PN mean was more extreme-i.e., it was more negative than the NP mean was positive, although the difference was significant only for the 2-6 pair $(t=2.47 ; \mathrm{df}=58 ; \mathrm{p}<.05)$.

The number of $S s$ who remembered more negative than positive behaviors by the stimulus person on the delayed trial was compared with the number who remembered more positive than negative. Only the medium-intensity group showed a significant difference, which favored negative memories $\left(\chi^{2}=11.26 ; \mathrm{df}=1\right.$; $\mathrm{p}<.01)$. The high-intensity group yielded an insignificant difference in the same direction. The low-intensity group, however, contained an insignificantly greater proportion of Ss with more positive memories. Since memories were not always congruent with the final negative ratings, therefore, the negative bias is evidently not simply a function of selective recall.

\section{Effects of Intensity}

While the same pattern of changes over trials was found at all levels of stimulus extremeness, the least intense stimuli (the 3.5 paragraph pair) yielded means on Trials 2 and 3 that were less extreme than those found for the more intense stimuli. A single exception occurred on the third PN trial, where there was no difference. Ratings based on the 2-6 and 1-7 paragraph pairs did not differ on either trial.

The possibility had been considered that with very disparate descriptive materials, $S$ s might not be able to form an overall impression of the stimulus person. To answer this question an analysis was made of the paragraphs describing C's character that Ss wrote after the second trial. Two judges unfamiliar with the hypothesis sorted all paragraphs into the explanatory categories used by Richey et al (1967). Judges agreed on 95\% of the paragraphs. Among those reliably sorted, only $21 \%$ were judged to show no resolution. Of the latter, $44 \%$ came from the highest-intensity groups, $50 \%$ from the medium, and $6 \%$
Table 2

Mean Ratings of Univalent Paragraphs Over Trials

\begin{tabular}{|c|c|c|c|c|}
\hline \multirow[b]{2}{*}{ Paragraph } & \multirow[t]{2}{*}{ Trial 1} & \multicolumn{2}{|r|}{ Trial 2} & \multirow[b]{2}{*}{$\begin{array}{c}7 \text { th } \\
\text { Day } \\
\text { M }\end{array}$} \\
\hline & & $\begin{array}{c}\text { Same } \\
\text { Day } \\
\text { M }\end{array}$ & $\begin{array}{c}4 \text { th } \\
\text { Day } \\
M\end{array}$ & \\
\hline Positive (6) & $\begin{array}{l}6.20 \\
6.00 \\
6.20\end{array}$ & $\begin{array}{c}5.90 \\
- \\
-\end{array}$ & $\begin{array}{c}- \\
5.80 \\
-\end{array}$ & $\overline{-}$ \\
\hline Negative (2) & $\begin{array}{l}1.90 \\
1.60 \\
1.80\end{array}$ & $\begin{array}{c}1.70 \\
= \\
-\end{array}$ & $\begin{array}{c}- \\
1.60 \\
-\end{array}$ & $\begin{array}{c}- \\
1.90\end{array}$ \\
\hline
\end{tabular}

from the low. Evidently, therefore, while the "credibility gap" is greater at the medium and high levels, even the 1 and 7 paragraph combination is reconcilable to most Ss.

Test of Alternative Hypothesis

To test if results obtained might simply represent a regression effect that would have been found in a week even with univalent information, two additional groups of $30 \mathrm{Ss}$ each were presented with positive (P6) or negative (N2) paragraphs only. One third of each group was retested at each of three intervals: $1 \mathrm{~h}, 4$ days, and 7 days. Mean ratings are given in Table 2 . Separate 3 by 2 repeated-measures analyses of variance were done for ratings based on each paragraph. Results indicated no significant effects of interval or trial and no interaction of the two in either analysis. These results are interpreted as evidence that ratings based on univalent data do not show significant regression effects within the period studied, and that results obtained in the study proper are dependent upon the combination of disparate information.

The major conclusion of this study, that negative information has a disproportionate influence on impressions of character, is not predicted by either an uncorrected summation or simple averaging theory of information integration. Neither has specifically assigned greater weight to negative than to positive information. Presumably either theory could incorporate such a correction if the need were indicated by relevant empirical data. Findings in this area, however, have generally appeared consistent with an assumption of equal positive and negative influence. In regard to the disparity between these findings and those of the present study, it should first be noted that this study and that of Richey et al have dealt exclusively with impressions of character. The negative bias observed may prove to be unique to moral-ethical evaluations. Other investigators have often combined personality, character, and ability data in the stimulus materials. 
Next, it should be remembered that the present investigators have studied reactions to specific. concrete behaviors, whereas many other studies in the area have used lists of adjectives as the descriptive stimuli. When an $S$ accepts a trait, e.g., "considerate," as given, he is already one step removed from the kind of problem he faces in the present study, in which he is presented with evidence that the stimulus person sometimes behaves considerately and sometimes inconsiderately. It should also be noted that the negative bias observed has appeared most strongly as a delayed effect. Most of the studies in this area have used immediate ratings only; thus there would have been no opportunity to observe a delayed effect, even supposing it had occurred with the type of stimulus materials used.

Finally. there is some recent evidence that even with different types of stimulus materials and procedures, negative information may be more heavily weighted. Wyer \& Watson (1969) note that results they obtained with judgments of likeability of sets of personality traits "could ... indicate that negative adjectives have a disproportionately greater influence upon evaluations than would be predicted on the basis of their relative polarization [p. 25]." The same authors cite a relevant study by Feldman (1966) which reports a correlation of -.69 between the evaluation of a given adjective and its influence on ratings of pairs of adjectives that include it.

\section{REFERENCES}

ANDERSON, N. H. Averaging versus adding as a stimulus-combination rule in impression formation. Journal of Fxperimental Psychology, 1965, 70, 394-400.

ASCH. S. E. Forming impressions of personality. Joumal of Abnormal \& Social Psychology, $1946,41,258-290$.

FELDMAN, S. Motivational aspects of attitudinal elements and their place in cognitive interaction. In S. Feldman (Ed.). Cognitive consistency: Motivational antecedents and behavioral consequents. New York: Academic Press, 1966. Pp. 75-108.

FISHBEIN. II. An investigation of the relationships between beliefs about an object and the attitude toward that object. Human Relations, 1963, 16, 233-239.

FISHBEIN, M., \& HUNTER, R. Summation versus balance in attitude organization and change. Journal of Abnormal \& Social Psychology, 1964, 69, 505-510.

OSGOOD, C. E., SUCI, G. J., \& TANNENBAUM, P. H. The measurement of meaning. Urbana: University of Illinois Press, 1957.

RICHEY, $M$. H., MCCLELLAND, L., \& SHIMKLNAS, A. M. Relative influence of positive and negative information in impression formation and persistence. Journal of Personality \& Social Psychology, 1967, 6 32-327.

ROSENKRANTZ, P. S., \& CROCKETT, W. H. Some factors influencing the assimilation of disparate information in impression formation. Journal of Personality \& Social Psychology. $1965,2,397.402$

WYER, R. S. \& WATSON, S. F. Context effects in impression formation. Journal of Personality \& Social Psychology, 1969.12. $22-3$.

\title{
The effects of form class on the free recall of contiguous items*
}

\author{
LINDA A. NELSON and DONALD H. KAUSLER \\ Saint Louis University, St. Louis, Mo. 63103
}

Noun (N) and verb (V) items were exposed contiguously as pairs during the input phases of a free-recall task, with the list containing equal numbers of $\mathrm{N} \cdot \mathrm{N}, \mathrm{V} \cdot \mathrm{V}, \mathrm{N} \cdot \mathrm{V}$, and V-N pairs. Recall of $\mathrm{N}$ items was superior to recall of $\mathrm{V}$ items for homogeneous pairs (N-N and V.V), but not for heterogeneous pairs (N.V and V-N). The results supported the hypothesis that recall of items in homogeneous pairs is mediated by associative habits, whereas recall of items in heterogeneous pairs is mediated by grammatical habits.

A number of studies (e.g., Glanzer, 1962; Shapiro \& Palermo, 1967; Simpson, 1965; Stanners, 1969) have found differential rates of learning for the various

* This study is based upon a thesis submitted by the first author to the Graduate School, Saint Louis Liniversity, in partial fulfillment of the requirements for the Master of Science degree. grammatical form classes. Both associative and grammatical habits have been postulated as being mechanisms underlying the effects of form class on verbal learning (Glanzer, 1962; Rosenberg, 1965; Stanners, 1969). In terms of the distinction made by Rosenberg (1965) and Stanners (1969), associative habits are "... the kind of verbal habits that have been revealed by cultural norms of free association... [Rosenberg, 1956, p. 123]," whereas grammatical habbits are "... those which underlie the sequential behavior corresponding to grammatical rules [Stanners, 1969, p. 99]." The present experiment was concerned with the differential efficacy of these mechanisms in a multitrial free-recall task when noun $(\mathrm{N})$ and verb (V) form classes served as items.

The free-recall task involved a modification of the usual free-recall input procedure in which items are presented individually for study and in a different serial order for each input phase. The modification consisted of exposing items contiguously as pairs during inputs, with both the interpair item content and the intrapair spatial (left-right) assignment of items remaining constant across trials. Outputs, however, consisted of the standard recall of single items in any order.

The list contained an equal number of $\mathrm{N}$ and $\mathrm{V}$ items, which entered, in turn, into equal numbers of $\mathrm{N}-\mathrm{N}, \mathrm{N}-\mathrm{V}, \mathrm{V} \cdot \mathrm{N}$, and $\mathrm{V} \cdot \mathrm{V}$ pairs. Generalizing from earlier studies on form class (e.g., Simpson, 1965), total recall of $\mathrm{N}$ items was expected to exceed total recall of $\mathrm{V}$ items. Of greater interest, however, was the expected difference in recall between $\mathrm{N}$ and $\mathrm{V}$ items when they occurred as components of heterogeneous pairs (i.e., N.V and V-N pairs) and when they occurred as components of homogeneous pairs (i.e., $\mathrm{N}-\mathrm{N}$ and $\mathrm{V}-\mathrm{V}$ pairs). A heterogeneous pair of items (either N-V or V-N) forms a grammatical sequence characteristic of natural language, and it is likely to be learned as a unit (Glanzer, 1962). Consequently, the recall differential between $\mathrm{N}$ and $\mathrm{V}$ items should be negligible for heterogeneous pairs. On the other hand, a homogeneous pair of items (either N-N or V-V) does not form a grammatical sequence, and it is unlikely to be learned as a unit. Instead, associative habits akin to those accounting for the preponderance of paradigmatic associations in word-association norms are likely to be activated when contiguous homogeneous items are exposed. Since N-N clustering generally exceeds V.V clustering in free-recall learning (Stanners, 1969), N-N associations in the present situation are likely to accrue strength at a faster rate than V-V associations. Since incre ments in interitem associative strength are $\mathrm{pl}$ 'sumed to underlie increments in free recall (Tulving, 1968), recall of homogenecus $\mathrm{N}$ items was expected to exceed recall of homogeneous $\mathrm{V}$ items.

\section{LISTS}

The total population of Thorndike-Lorge (1944) high-frequency (A and AA) words, six to eight letters in 